11. Cridland, B.-" A Case of Glassblowers' Cataract in a Puddler (Ironworker)." Ophthalmoscope, Vol. XIII, p. 125, 1915.

12. Cridland, B. - "A Second Case of Glass-workers' Cataract in a Puddler (Ironsmelter)." Ophthalmoscope, Vol. XIV, p. 25, 1916.

13. Cridland, B.- 'The Occurrence of Glass-workers' Cataract in Puddlers (Ironsmelters)." Brit. Jl. Ophthal.. p. 193, May, 1921.

14. Roberts, B. H. St. Clair.- "A Series of Cases of Glass-blowers' Cataract occurring in Chainmakers." Brit.Jl. Ophthal., p. 210, May, 1921.

15. Healy, James J. "The Prevalence of Lenticular Opacities in the Eyes of Tinplate Millmen." Brit. Jl. Ophthal., p. 194, May, 1921.

16. Brinton, A. G.- "Discussion on Industrial Cataract." Ophthal. Soc. of the United Kingdom. Brit.Jl. Ophthal., p. 269, June, 1922.

The following may also be consulted :-

Chicago Ophth. Soc. "Discussion on Exposure of Eye to Light Rays." Amer. Jl. Ophthal., p. 49, Jan., 1922.

Birch-Hirschfeld.-Arch. f. Ophthal., Vol. LXXI, No. 3, 1909.

Abstract Bulletin of Nela Research Laboratory Works of G.E.C., Cleveland, Ohio. "Glasses for Protecting the Eyes in Industrial Processes." Brit. Jl.Ophthal., p. 244, May, 1920.

van der Hoere, J.-Chicago Ophthal. Soc., Oct, 24, 1921. " Affections of the Eye induced by Undue Exposure to Light Rays," Amer. Jl. Obhthal., p. 49, Jan., 1922

Stein, Dr. L.- "Untersuchungen uber Glasblaserstar." Arch. f. Augenheilk., Vol. LXXIV, p. 53, 1913. Ophthal. Rev., Vol. XXXIII, p. 12, Jan., 1914.

Parsons, J. H.-Roy. Soc. Med., Dec. 3, 1913. " Demonstration of Specimens of Crookes' Glass." Ophthal. Rev., Vol. XXXIII, p. 28, Jan., 1914.

"Cataract in Iron workers." Brit. Jl. Ophthal., p. 224, May, 1921.

Cramer, Dr. E. - "On the Origin and Clinical Peculiarities of Giass-blowers' Cataract." Klin. Monatsbl.f. Augenheilk., Jan., 1907.

Chick and Martin.-Jl. Physiology, Vol. XL., p. 404, 1910.

Correspondence on subject of "Cataract in Glass-workers." Ophthalmoscope, Vol. XIV, p. 109, 1916.

\title{
ON MACULAR PERCEPTION IN ADVANCED CATARACT
}

\author{
BY \\ George Young \\ COLCHESTER
}

IN the June, 191\%, number of this Journal I published a brief note on a test for macular perception in advanced cataract, which had proved useful to me. To-day I wish to describe more fully the way in which I perform it now, and, as a prelude, will introduce such a concrete case as would call particularly for a test of this nature in practice: one in which the question becomes of vital importance, and the conditions make it most essential to be able to form a sound opinion on the macular function before advising an operation, there being no second eye to call upon in case of a disappointing result, and the possibility of bilateral macular disease being present.

A patient presented himself to me with a senile cataract in his right eye, so advanced that the whole nucleus of the lens was opaque, and the red reflex was limited to the periphery. No trace 
of fundus details in the central portion could any longer be seen. Vision equalled hand movements, light projection was good, the tension was on the soft side. His last prescription-with valued signature-was - $18 \mathrm{D}$ sph., and the patient stated that he never could see signs, or recognize people across the street, even with

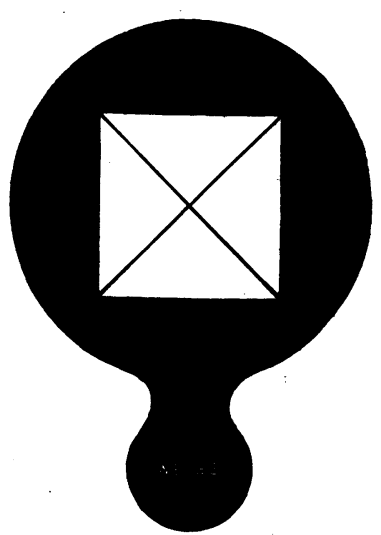

Fig. 1.

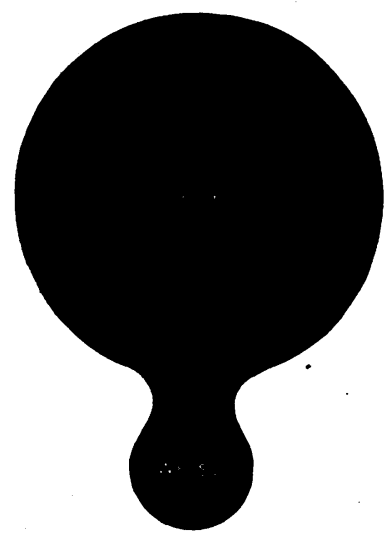

Fig. 3.

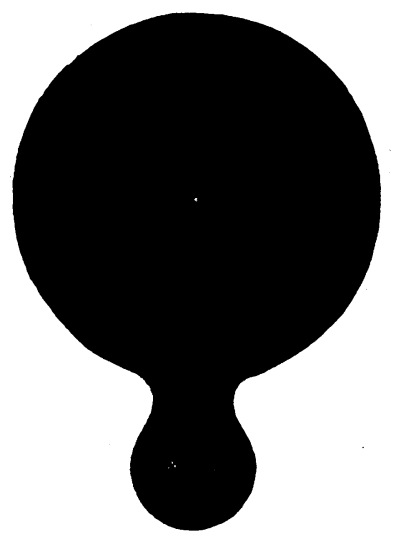

FIG. 2.

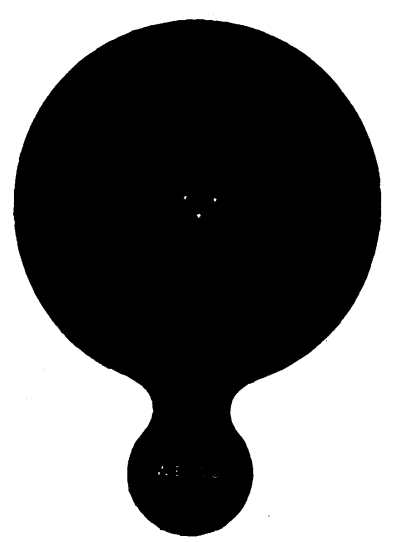

Fig. 4.

glasses. The left eye was less myopic, with the lens intact, but showing extensive myopic choroiditis: It had no distant form vision with any glass, and no Jaeger between his punctum remotum and punctum proximum. Right on the macula a patch of pigmented choroiditis had developed, three cornered, shaped somewhat like the map of Sicily, about half a dozen vessels' diameters in size. With this condition, and also a poor physique, a bad health record, angiosclerosis and high blood pressure, and the patient's additional statement that his right eye had always been his " poor" eye, we could ordinarily hold out but faint hopes of a 
successful operation. Surely we exonerate any surgeon who would hesitate to advise operation, and such had been the case here.

I select this case, though I might choose others which ended happily, for the reason that it is hardly possible to find one in which it became more essential to form a conclusive opinion, as to the state of the second macula lutea. This patient passed my macular test brilliantly. It was the one clinical sign which determined me not only to urge an operation, but also enabled me to prognosticate a favourable result. I performed a combined extraction of the right lens with an intracorneal incision, on July 4, 1921. The visual result was brilliant, and lasted so till my observation of October 10,1921, which was as follows :-

R.V. unaided, $6 / 36$ c. + 1.50 D. Sph. -6.50 D. Cyl. $75^{\circledR} 6 / 9$ and J.1 $\bar{c} .+6.50$ D. Cyl. $165^{\circ}$.

He went about ordinarily without glasses, seeing better with the naked eye than he had ever seen before with glasses. (That he subsequently, through unpardonable carelessness and bad behaviour, detached the whole lower half of his right retina, and that neither repeated galvano-cautery nor rest has been able to cure it, is indeed a sad tragedy, but it does not affect the value of the macular test.)

The test I now carry out as follows :-The outfit required is very simple, consisting of four discs which fit the trial frame.* The first disc to be used is a cross thread and merely serves to secure an exact centering of the trial frame on the patient's face. I use Lang's frame, which enables one with a few simple movements, by means of its two set screws, to get the cross thread exactly opposite the centre of the pupil.

This disc is then removed and the next is put in its place, which is perforated by a single pinhole exactly at the centre. In a dark room the patient is then brought quite close up to a frosted electric bulb, so close that the disc all but comes in contact with it. The Thorington chimney, with the diaphragm at its widest, is admirable for this purpose. The patient is then requested to look for a spot of light, which often is said to look like a little moon. Then, if he has seen it, the next disc, which is perforated by two pinholes, is placed in position, one at each end of a diameter of an exactly central circle of $1.5 \mathrm{~mm}$. radius-in other words, two pinholes $3 \mathrm{~mm}$. apart-and the patient is requested to say how many spots or moons he sees now. If he sees them they may look like two moons overlapping each other, and if the disc is now revolved in the frame he can be made to say when the moons are side by side, or oblique, and which way oblique, or whether they are one

${ }^{*}$ To be obtained from John Weiss \& Son, Ltd., 287, Oxford Street, W.1 
above the other. Finally, the disc with three holes, one at each angle of an equilateral triángle, also within a circle of $3 \mathrm{~mm}$. diameter, is chosen. Three overlapping moons should be seen, and by rotating the disc the patient may state whether they stand with one above and two below-like A-or two above and one below-like $\mathrm{V}$.

If this test is negative it does not exclude a sound macula. But if it is positive I believe it certainly must prove that the function of the macula is present, for no such precise statements could be given without direct fixation. Simple experiments show that accurate counting without absolutely direct fixation is impossible. In private practice and with the more intelligent out-patient I have found the test very useful and easy, and when it is positive I now recommend my patient to undergo an operation with far more conviction than formerly, feeling, as I do, that there is definite clinical evidence for the soundness of the macula lutea. Before I devised this test I was never convinced. I therefore hope it will prove useful and helpful to many others.

\title{
MONOCULAR OPTIC NEURITIS
}

\author{
BY \\ Leslie Buchanan, M.D. \\ GLASGOW
}

IN August, 1919, I was asked to see a young woman who had suddenly lost the sight of the right eye. I saw her on a Monday night and she gave the following history :-

On the Saturday previous she had gone a long motor drive without any adequate preparation in the way of wraps, and was sitting with her right side to the engine. It was a very cold day and she felt numb and chilled when she reached home. She had a slight headache and retired early that evening. Next morning the headache was still present when she rose, and whilst dressing she discovered that the vision of the right eye was not so good as it had been.

The defect of vision alarmed her, and she stayed indoors all day but the sight got steadily worse, and, by evening, she could see very little with this eye. She decided to come home (from Harrogate) at once and did so next day.

On arrival she saw her medical adviser, who found that she was almost entirely blind of the right eye, and advised her to see an ophthalmic surgeon without delay. She came to me that evening and I found that perception of light, even, was abolished. 